Teknokultura. Revista de Cultura Digital y Movimientos Sociales

ISSNe: $1549-2230$

http://dx.doi.org/10.5209/TEKN.64984

\title{
The threat of surveillance capitalism
}

\author{
Chris H. Gray ${ }^{1}$
}

Recibido: 7 de julio 2019 / Aceptado: 22 de octubre 2019 Open peer reviews

\begin{abstract}
Using Shoshana Zuboff's 2019 book, The Age of Surveillance Capitalism, the essay explores this latest form of capitalism and Zuboff's claims about its organization. Her arguments are compared and contrasted with David Eggers novel, and the movie that came out of it, called The Circle, as well as other perspectives on capitalism (Marx, Barry Unsworth's Sacred Hunger) and the current dominance of social media companies (especially Alphabet/Google, Facebook, and Amazon) from Evgeny Morozov, Natasa Dow Schüll, Zeynep Tufekci, Steve Mann and Tim Wu. Zuboff's description and critique of Surveillance Capitalism is a convincing and important addition to our understanding of the political economy of the early 21 st Century and the role of giant monopolistic social media companies in shaping it.
\end{abstract}

Keywords: behavioural surplus; Shoshanna Zuboff; social media.

\section{[es] La amenaza del capitalismo de la vigilancia}

Resumen. A partir del libro de Shoshana Zuboff de 2019, The Age of Surveillance Capitalism, el ensayo explora esta última forma de capitalismo y las afirmaciones de Zuboff sobre su organización. Sus argumentos se comparan y contrastan con la novela de David Eggers, y su adaptación a la gran pantalla en la película El Círculo [The Circle], así como otros analistas del capitalismo (Marx, Barry Unsworth's Sacred Hunger) y, en particular, del dominio actual de las compañías de redes sociales (especialmente Alphabet/Google, Facebook y Amazon) como Evgeny Morozov, Natasa Dow Schüll, Zeynep Tufekci, Steve Mann y Tim Wu. La descripción y crítica de Zuboff acerca del capitalismo de vigilancia es un excelente referente para comprender la economía política de principios del siglo XXI y el protagonismo del monopolio gigantesco de las redes sociales generalistas en esta economía.

Palabras clave: excedente de comportamiento; Shoshanna Zuboff; redes sociales.

Summary. 1. Imagining the end of capitalism. 2. Going full circle. 3. A horrible sacred hunger. 4. References.

Cómo citar: Gray, C. H. (2019). The threat of surveillance capitalism. Teknokultura. Revista de Cultura Digital y Movimientos Sociales, 16(2), 265-276.

\section{Imagining the end of capitalism}

Surveillance capitalism operates through unprecedented asymmetries in knowledge and the power that accrues to knowledge. Surveillance capitalists know everything about

\footnotetext{
1 University of California (EEUU)

E-mail: chris.hablesgray@stanfordalumni.org
} 
$u s$, whereas their operations are designed to be unknowable to us. They accumulate vast domains of new knowledge from us, but not for us. They predict our futures for the sake of other's gain, not ours (Zuboff. 2019a, p.11).

If you use apps on your smart phone you are probably being monitored by over 5,000 e-trackers per week. Yes, iphones too. And tracking on your computers as well, of course, and your accounts in the cloud. It is this type of data that is used to target me and you to sell us music, politicians, books, games, and so much more. So no wonder Shoshana Zuboff's Surveillance Capitalism is so scary. She has analyzed the dominant companies of our age (Google, Facebook, Amazon, Apple, Microsoft/ LinkedIn, Verizon/Oath) and argues convincingly that they are producing a new economic form: Surveillance Capitalism.

While the definition of Surveillance Capitalism that begins her book posits it as "rogue" (iv) her analysis belies that conclusion. As she points out just a few pages later (Zuboff, 2019a, p. 9), surveillance capitalism replaces "the continuous intensification of the means of production" of industrial capitalism with "the continuous intensification of behavioral modification". The next paragraph begins by arguing that Google "invented and perfected" this new type of capitalism, just as General Motors did for "managerial capitalism". A claim she supports in horrifying detail in hundreds of pages of analysis. So, not so rogue really, except in the sense that all capitalism is rogue.

What she never quite manages is to define capitalism itself clearly, nor clarify the many different forms it seems to take, as in the quick slide from "industrial" to "managerial" capitalism in just one page noted above. But what she does do is build an analytic framework for understanding how these companies (and others in their orbits) have become so powerful, and flesh it out with shocking admissions from the key corporate players who are making this real. What is revealed is a bit more complicated than the cute "if it is free, you are the product". She explains that the product isn't us, but rather data about our behavior which leads to predictions about what we might want and do in the future and, more and more, ways to shape who we are. So, surveillance capitalism's actual customers are the enterprises that trade in its markets for future behavior (Zuboff, 2019, p. 10). Often critics blame the hardware and software, the tech, for the way the world is. Yes, new techs come out of old political economies and have designed-in affordances for profit and hierarchy, but the past is not definitive. In the end, it isn't the tech, it is what is done with it.

Surveillance capitalism is a market form that is unimaginable outside the digital milieu, but it is not the same as 'digital' ...the digital can take many forms depending upon the social and economic logics that bring it to life. It is capitalism that assigns the price tag of subjugation and helplessness, not the technology (Zuboff, 2019a, p. 15).

Zuboff calls the network of social media companies "Big Other", and argues they have developed a new form of instrumentalist power: Instrumentarianism and its materialization in Big Other signal the transformation of the market into a project of total certainty, an undertaking that is unimaginable outside the digital milieu and the logic of surveillance capitalism (Zuboff, 2019a, p. 20). Surveillance Capitalism starts with knowledge. Monopolizing knowledge. Instead of the division of labor 
that undergirds industrial capitalism, there is a new division of learning. A restricting of knowledge, authority and power that Zuboff (2019a, p. 181) maps over into three fundamental questions:

1) Who knows? Who gets to learn what?

2) Who decides? Who decides who gets to learn and what?

3) Who decides who decides? Who answers the first two questions?

The learning here isn't primarily the formal education we all go through. That is important but it is a well-known process, complicated, with deep historical roots. Rather, it is more about all the new knowledge our machines can now collect and analyze. It is Big Data. And Surveillance Capitalism needs the unfettered access to all they can collect in order to produce the surplus value they rely on for profits and the power to make more profits.

This surplus is in knowledge of human behavior. This is the monitoring of our emotional lives, the lived libidinal economy, and turning it into a behavior surplus.

Zuboff sees that besides the older capitalist "laws" (her quote marks) that include "competitive production, profit maximization, productivity, and growth" the new logics of accumulation are "defined by extraction and prediction" of human behavior. This leads to

...a necessary construction and elaboration of means of behavioral modification that incorporate its machine-intelligence-based 'means of production' in a more complex system of action and the ways in which the requirements of behavioral modification orient all operations toward totalities of information and control, creating the framework for an unprecedented instrumentarian power and its societal implications (Zuboff, 2019a, p. 67 -italics in original).

The surveillance capitalist's use free market claims to hold off regulators from their domination of digital cultural life as they suck up investment capital to increase the efficiency of their colonization of the social. So it is clearly a capitalist enterprise and can help explain why so many people today say it is impossible to imagine a world without Facebook, Amazon, and all the rest. Is this an aspect of the oft told joke that it is easier to imagine the end of the world than the end of capitalism?

Maybe, if you are a Marxist. Marxism needs capitalism to explain the world. And although she isn't a Marxist, which is a "Modern utopia" in her view, (Zuboff, 2019a, p. 222), capitalism seems a natural force to Zuboff as well, somehow being beyond challenge. She can only label certain forms of Capitalism as evil, but not the system of putting capital at the center of human culture. Capital, which hasn't even existed for most of humanity's story, and which for most people remains an abstract and not very important concept. It is a bit surprising Zuboff has trouble imaging the end of Capitalism. Her excellent account of how work has been changed by capitalism and automation, In the Age of the Smart Machine, includes a compelling description of the destruction of natural cycles of work (agricultural and craft), worker control of skill (guilds in particular) and the appropriation of the commons by British elites as they created the first capitalism. 
That was only a few hundred years ago. Obviously, capitalism is not forever, it has a history and a future and some day it will end. But for now we have to deal with the latest form it has morphed into. Zuboff summarizes it thus:

Surveillance capitalism departs from the history of market capitalism in three startling ways. First, it insists on the privilege of unfettered freedom and knowledge. Second, it abandons long-standing organic reciprocities with people. Third, the specter of life in the hive betrays a collectivist societal vision sustained by radical indifference and its material expression in Big Other (Zuboff, 2019, p. 496 --original emphasis).

\section{Going full Circle}

Mae believes, wholeheartedly, that the Circle's way is the way - that life is easier, better, and more fulfilling when privacy is all but eradicated. In fact, at the end of the novel, Mae hopes one day private thoughts are able to become public knowledge as well (Reilly, 2017).

\section{Maps Make Empires!}

Paraphrasing John B. Harley (Zuboff, 2019, p. 155).

In David Eggers (2013) powerful and disturbing novel The Circle, a young "Customer Experience" tech named Mae joins a company called The Circle. It dominates the social media and informational economies, combining the power of Alphabet (Google's holding company), Apple, Amazon and Facebook. It is a higher order dystopia, like Brave New World. The entrepreneurs of The Circle relentlessly claim that their intimate and pervasive collection of all possible personal information is for the public good. It is just an accident (or fate?) that following their principlesSecrets are Lies, Sharing is Caring, and Privacy is Theft-makes them incredibly rich and powerful. They take over voting, crowd-source a hyper-panoptic culture to enforce everything from recycling to an end of privacy, and end up dominating (one might say even absorbing) most of the economic and social life of the world. Mae not only comes to accept The Circle, but become one of its leading advocates and joins upper management, called the Gang of 40 .

For several years we required The Circle as summer reading for frosh at my STEM College at the University of California at Santa Cruz. A third of my students thought it was a utopia, a third thought it dystopian, a third were very confused indeed. The same rough divisions are to be found in their attitudes toward the social media behemoths The Circle warns against.

In the real world, Shoshanna Zuboff admonishes us that:

It is important to understand that surveillance capitalists are impelled to pursue lawlessness by the logic of their own creation. Google and Facebook vigorously lobby to kill online privacy protection. Limit regulation, weaken or block privacy-enhancing legislation, and thwart every attempt to circumscribe their practices 
because such laws are existential threats to the frictionless flow of behavioral surplus (Zuboff, 2019a, p. 105).

Clearly, The Circle's corporate principles are alive and metastasizing in Google, Facebook, Microsoft, Amazon, Apple and beyond. I already liked The Circle but after reading The Age of Surveillance Capitalism I now consider it is as important a work as Brave New World. If the human future goes badly, there won't be one. Pretty bad is collapse (aka post-apocalypse). But if civilization makes it through the next 50 years my great fear is that it will be more of a combination of Brave New World and The Circle than 1984. Orwell's great nightmare is just too far removed from what might happen, and from what students imagine is possible. But turning the source of their greatest pleasures into dystopia, now that sometime shocks them.

One of the dissidents to this regime of surveillance capitalism is Mae's oldest friend Mercer. Before he is hounded to death by Mae and a Circle-catalyzed mob demanding access to his life, he explains to Mae why he doesn't want to join.

I'm social enough. But the tools you guys create actually manufactureunnaturally extreme social needs. No one needs the level of contact you're purveying. It improves nothing. It's not nourishing. It's like snack food. You know how they engineer this food? They scientifically determine precisely how much salt and fat they need to include to keep you eating. You're not hungry, you don't need the food, it does nothing for you, but you keep eating these empty calories. This is what you're pushing. Same thing. Endless empty calories, but the digital-social equivalent. And you calibrate it so it's equally addictive (Eggers, 2013, pp. 133134 -original emphasis).

As with actual gambling machines, fast food, mass media, electronic games and many other aspects of postmodern life, social media are designed to be addictive (Schüll, 2014). So it is no surprise that at the end of the book, Mae has gotten her friend killed, alienated her parents (she bugged their house revealing their sex life to the world), and betrayed the Circle's one ethical founder, who was trying to kill the monster he made by revealing that the other two founders, Stenton and Bailey were not monitored themselves and were planning on taking over the world...for everyone's good, of course. On the last page (Eggers 2013, p. 491) she is at the bedside of her unconscious friend Annie, the woman who got her the job at The Circle who has had a breakdown. Mae is aggrieved.

Another burst of color appeared on the screen monitoring the workings of Annie's mind. Mae reached out to touch her forehead, marveling at the distance this flesh put between them. What was going on in that head of hers? It was exasperating, really, Mae thought, not knowing. It was an affront, a deprivation, to herself and to the world. She would bring this up with Stenton and Bailey, with the Gang of 40 , at the earliest opportunity. They need to talk about Annie, the thoughts she was thinking. Why shouldn't they know them? The world deserved nothing less and would not wait (Eggers 2013, p. 491). 
The movie, which has its virtues, turns this ending on its head and Mae (Emma Watson staying true to her Hermione character) exposes Stenton and Bailey for the evil, greedy, hypocrites they are. But that's Hollywood, not literature (Reilly, 2017). In the real world, as in the book, things look a great deal worse. For as Zuboff documents, the next step of Surveillance Capitalism is the quantification of the physical world and, no doubt, our private mental worlds will follow right after if at all possible. Considering the progress being made with "mind reading" neuroscience research using many of the same digital technologies as surveillance capitalism (machine learning, big data on human mentation/behavior, big data mining and manipulation) it probably will be soon (Gray, 2014).

The canary in the coal mine is the fat little Pokémon. Collecting, and using, real world data is the inevitable next step. It started with Google Maps. Zuboff quotes Brian McClendon, Goggle Map's senior product manager, who remarked in 2012:

If you look at the offline world, the real world in which we live, that information is not entirely online. Increasingly as we go about our lives, we are trying to bridge that gap between what we see in the real world and [the online world], and Maps plays that part (Zuboff, 2019a, p. 150-151).

And why is Google so anxious to bridge that gap, not just with Google Maps but also street view and even giving backpack cameras to tourist boards and hiking clubs to capture images that were once "off the grid" (Zuboff, 2019, p. 152)? Because the real world is data that can be leveraged for much more power. As Zuboff explains, this is about

...the migration from an online data source to a real-world monitor to an advisor to an active shepherd-from knowledge to influence to control. Ultimately, Street View's elaborate data would become the basis for another complex of spectacular Google incursions: the self-driving car and "Google City"... These programs aim to take surplus capture to new levels while opening up substantial new frontiers for the establishment of behavior futures markets in the real world of goods and services. It is important to understand that each level of innovation builds on the one before and that all are united in one aim, the extraction of behavior surplus at scale (Zuboff, 2019a, p. 153).

Add in phone data and all you can get from wearables, such as the progeny of Google Glass, and AR games like Pokémon and the new Harry Potter spin-off "Wizards Unite" and you are sucking up an incredible amount of real world/human behavior data. This is why all of these companies invest massively in what they call artificial intelligence, but which is better termed "machine learning", as Zuboff labels it. After all, it isn't really intelligence in any human sense that they are creating, it is the ability to mimic intelligence enough to interact with humans (Hi Alexa! Hi Siri!) and so collect immeasurable amounts of information.

Google Maps fits into an analogy Zuboff uses throughout her text: colonization. Mapping was integral to European colonialism after all. Mapping is part of conquest after all. And for conquest to be worthwhile, there must be control of what (whom) 
is captured, or the colonizers will have failed. All the suffering they have inflicted, including the sacrifices they have endured, will not be worth it unless they can be satisfied.

\section{A horrible sacred hunger}

We are learning now to write the music, and then we let the music make them dance. We can engineer the context around a particular behavior and force change that way. Context-aware data allow us to tie together your emotions, your cognitive functions, your vital signs, etcetera. We can know if you shouldn't be driving, and we can just shut your car down. We can tell the fridge, "Hey, lock up because he shouldn't be eating," or we tell the TV to shut off and make you get some sleep, or the chair to start shaking because you shouldn't be sitting so long, or the faucet to turn on because you need to drink more water (Anonymous Internet of Things designer in Zuboff, 2019a, p. 295-6).

See, nothing to worry about. Having your appliances boss you around is just for your own good... and the profit of "Big Other", of course. Drawing from psychology's discoveries such as operant conditioning and their own research, these helpful engineers have developed a whole suite of operationalized manipulations (in the form of algorithms) for "conditioning at scale". There are at least 93 such "tools" identified in an important analysis from 2014 (Lyons et al. in Zuboff, 2019, p. 621, n. 2) including: scheduled consequences, reward and threat, repetition and substitution, antecedents, associations, feedback and monitoring, goals and planning, social support, comparison of behavior, communication of natural consequences, self-belief, comparison of outcomes, shaping knowledge, regulation, identity, and overt learning. And it doesn't take much to get them to admit their goal is control. As "the chief data scientist for a much-admired Silicon Valley Education Company" told Zuboff, anonymously:

The goal of everything we do is to change people's actual behavior at scale. We want to figure out the construction of changing a person's behavior, and then we want to change how lots of people are making their day-to-day decisions. When people use our app, we can capture their behaviors and identify good and bad. Then we develop "treatments" or "data pellets" that select good behaviors. We can test how actionable our cues are for them, and how profitable certain behaviors are for us (Zuboff, 2019a, p. 297).

Where do they get the unmitigated gall to work toward this level of interference in people's actual lives? They use our lives as raw data which they consume and shit out as "data pellets" which manipulate us. What is their justification? Simple. It is profitable. If it makes money, they have every right to do it.

Money is sacred as everyone knows... So then must be the hunger for it and the means we use to obtain it. Once a man is in debt he becomes a flesh and blood 
form of money, a walking investment. You can do what you like with him, you can work him to death or you can sell him. This cannot be called cruelty or greed because we are seeking only to recover our investment and that is a sacred duty (Unsworth, 1992, p.176).

It is the insanity of justifying slavery based on this sick logic that drives Barry Unsworth's great novel, Sacred Hunger. But is our world any less insane? Yes, kleptocrats such as Putin and cult-of-personality dictators (Kim Jong-un) don't really need to justify their actions, but in a democracy domination is a bit more difficult. By claiming any innovation that is profitable, no matter how "disruptive", is not just justified, it is better for everyone and therefore it is morally good to desire this profit, is the myth that makes capitalism so particularly dangerous. This desire to do well for oneself (which means good for all, doesn't it?) is the "sacred hunger" that drives Surveillance Capitalism's colonization and domination of our personal lives. At the heights of many economies of the world today are kleptocratic gangs, rapacious power brokers, corrupt politicians, cults of personality, national militaries as organized crime and other obvious authoritarians. But at the beating heart and bleeding edge of the dominant economy, the U.S. imperial system, are corporate titans who think the looting of living nature and human culture is not just inevitable, but laudable! For all her powerful analysis of this developing nightmare, Zuboff doesn't really explore the hungers, far from actually sacred, that drive the principle players of Google, Facebook, Amazon and their allies, "Big Other" she calls them. She comes close at times, especially in her argument that the principles in play at the heart of Google's business plan, a series of declarations about their "freedom" to exploit social relations (Zuboff, 2019, p. 176) closely follows the pattern of European colonialism. But she still seems a bit adrift in how horrible capitalism, and other exploitative forms, can be and are. Perhaps this is what leads to her excessive pessimism. Of course, things are terrible in many ways, and the rise of Surveillance Capitalism only makes most things worse. But she misses some key aspects by not putting Surveillance Capitalism firmly in the context of its development within the history of capitalism (with its origins in racist slavery, invented by Europe), modern finance by the Dutch, the British perfection of modern imperialism and the United States' invention of the currently dominant postmodern neo-imperialistic system.

Because this story also includes hope. It is the hope of the abolition of slavery, of the rise of worker's movements and the expansion of suffrage, the collapse of European colonialism and the British Empire and the decline of the American System, as it devolves into parody. The same creative destruction behind relentless capitalist reinventions of itself also opened the space for the rights of women, sexual liberation, environmentalism, and the decline of formal power for organized religious extremists.

Zuboff does look for hope in the reality that the target of capitalism is now human nature, having pretty much despoiled non-human nature: In the conquest of nature, industrial capitalism's victims were mute. Those who would try to conquer human nature will find their intended victims full of voice, ready to name danger and defeat it (Zuboff, 2019a, p. 525). But people did, and do, resist the destruction of nonhuman nature. Years ago we were warned by Blake about the Satanic Mills. Many others, poets and workers, mothers and ramblers, eco-activists and other rebels against ex- 
tinction, have made saving nature their priority. There is a dialectic at work (although not Hegelian and even less Marxist) so that each seductive (dreamy and nightmarish) step forward in industrialization and capitalization (two different things) is met with growing resistance.

So far, the exploitation of the many by the few has proven distressingly nimble. It doesn't help that this exploitation gets the credit for improved health, a decline in violence and poverty, and the growing rights of all sorts of humans when really this has happened almost in spite of capitalism and other forms of profit-taking, since it comes from the actual human work and invention that the masses of people do. The original sin of Surveillance Capitalism is baked into the affordances of the technologies by the profit motive. But these same techs can, if divorced from greed, empower citizens, enable liberatory hacking and disrupt not just markets, but reified political systems and their elitist domination. This is the yin to The Circle's yang. Tech makes their surveillance more powerful, and yet it makes our resistance strong-if used differently. If used not for profit but for sustainability, not for domination but justice, not out of anger and fear about our nature (and thus all nature) but rather-is there a better word?-love. But used.

Social media isn't just a form of exploitation; it also can be a tool of liberation. As Tufekci (2017) explains in her powerful book Twitter and Tear Gas: The Power and Fragility of Networked Protest:

Historian Melvin Kranzberg's famous dictum holds true: “Technology is neither good nor bad; nor is it neutral". Neither are technology's effects static; everything evolves as people invent, innovate, and appropriate technologies for their purposes. This dynamism does not mean that technology provides a level playing field, where each side is equally empowered and equally able to appropriate technologies for its purposes. Not only social forces determine the transformation-features and characteristics of technologies are relevant and these affordances are sometimes beyond the control of these technologies' designers. Any analysis must necessarily embrace this complexity and try to avoid the false dichotomies: optimists versus pessimists; utopians versus dystopians; humans versus technology. I am not arguing for some sort of "technological centrism," but simply for understanding the complex and at times contradictory relationship between different effects of digital technologies (Zuboff, 2019a, p. 262).

Coming at it from a different angle, the inventor activist academic Steve Mann has pointed out that we don't just have a Surveillance Society. Watching isn't just from above and sousveillance (watching from below) is now a powerful political and social force. We live in a Veillance Society (Mann and Ferenbok, 2013) and that has profound implications for not just Zuboff's analysis of Surveillance Capitalism, but for the human future.

Tim Wu's work is also a useful correction to some of Zuboff's worst elisions. For one thing, in The Attention Merchants he carefully traces the genealogy of Surveillance Capitalism back to advertising and this reveals that it is not as new an approach as Zuboff contends. As he sardonically remarks, "Since the rise of capitalism it has been known that capturing someone's attention could cause him (sic.) to part with some money".(9) Wu also worries much more than Zuboff does in this work, about 
the dangers of the propaganda/attention state, not just corporations that mobilize behavioral technologies.

But to give Zuboff her due, Wu misses just how great the danger is. He remarks at the end of The Attention Merchants,

If we desire a future that avoids the enslavement of the propaganda state as well as the narcosis of the consumer and celebrity culture, we must first acknowledge the preciousness of our attention and resolve not to part with it as cheaply or unthinkingly as we so often have. And then we must act, individually and collectively, to make our attention our own again and so reclaim ownership of the very experience of living (Zuboff, 2019a, p. 344).

Nice enough but it doesn't really convey the depth, the danger, of where we are now. So, Zuboff's is the more important book by far, not just because of her deeply supported analysis of Surveillance Capitalism. Not only does she see the danger as more existential even than "enslavement", she has described in useful detail the behavioral-libidinal economy of today's dominant economic organizations and the emergence of a Surveillance Economy. As she summarizes:

The commodification of behavior under the conditions of surveillance capitalism pivots us toward a societal future in which an exclusive division of learning is protected by secrecy, indecipherability, and expertise. Even when knowledge derived from your behavior is fed back to you in the first text as a quid pro quo for participation, the parallel secret operations of the shadow text capture surplus for crafting into prediction products destined for other marketplaces that are about you rather than for you. These markets do not depend upon you except as a source of raw material from which surplus is derived, and then as a targeted for guaranteed outcomes. We have no formal control because we are not essential to the market action. In this future we are exiles from our own behavior, denied access to or control over knowledge derived from our experience. Knowledge, authority, and power rest with surveillance capital for which we are merely "human natural resources (Zuboff, 2019a, p. 328 -italics in original).

Which, again, raises the question of why? What do the rich and powerful developers of Surveillance Capitalism want? To own more of San Francisco? To be on the cover of Wired? To own more houses everywhere? Here, the novel The Circle is helpful. The main evil owner of The Circle is played by Tom Hanks in the movie. Unlike the ending, this was a good choice, for the majority of owners and managers of Facebook, Google, Amazon, Apple, and Microsoft think of themselves as good guys, nice guys, and the kind of guys Tom Hanks plays in romcoms. They are filthy rich and getting richer, because they are smarter and whiter (and male, if not more masculine) than most other people, they feel they deserve it. They are entitled. And they are entitled to run society, actually, because in their expert opinion they can do it better than anyone else, as has been proven by the massive amount of wealth they have collected. They may have side projects that are laudable (the Gates are curing malaria) or debatable (Bezos of Amazon really wants to use his wealth and power to colonize space) but mostly they feel that they have earned the right to 
control society and they plan to exercise that right. Just as the Europeans (and that includes Americans and Australians) knew they had the right to go out in the world and impose their reality on the people already there, "Big Other" sincerely believe that they should remake the world in whatever way is most profitable to them.

Ironically, their "sacred hunger" is really an addiction. They have become rich and powerful making addictive technologies but they are blind to the reality that they are addicted themselves to their power to shape reality and addict others. And they won't stop until they are stopped.

As this book review essay goes to press, Facebook has announced it is creating its own currency, to be called Libra, and Shoshanna Zuboff (2019b) has published an article in The Guardian pointing out that we can control Facebook, Amazon and the rest of "Big Other", but we haven't even tried yet. So perhaps she isn't as pessimistic as I thought. Zuboff had done a great service to us all with her wonderful work and she is fundamentally right. It comes down to:

1) Who knows? Who gets to learn what?

2) Who decides? Who decides who gets to learn and what?

3) Who decides who decides? Who answers the first two questions? (Zuboff, 2019a, p. 181)

\section{References}

Eggers, D. (2013). The Circle, San Francisco: McSweeney's Books.

Gray, C. H. (2014). "Big Data, Actionable Information, Scientific Knowledge and the Goal of Control," Teknokultura. Revista de Cultura Digital y Movimientos Sociales 11(3), 529-54.

Reilly, K. (2017). "Why The Circle Should Have Stuck To Its Original Ending, Refinery29, May 1. Accessed July 1, 2019.

Lyons, E. J. et al. (2014). "Behavior Change Techniques Implemented in Electronic Lifestyle Activity Monitors: A Systematic Content Analysis," Journal of Medical Internet Research 16 , no. 8.

Mann, S. and Ferenbok, J. (2013). "New Media and the power politics of sousveillance in a surveillance-dominated World", Surveillance \& Society, vol. 11 (1/2). 18-34.

https://ojs.library.queensu.ca/index.php/surveillance-and-society/article/view/veillance

Morozov, E. (2019). Facebook's plan to break the global financial system, The Guardian, June 22, accessed June 23, 2019.

Schüll, N. D. (2014). Addiction by Design: Machine Gambling in Las Vegas, Princeton, NJ: Princeton University Press.

Tufekci, Z. (2017). Twitter and Tear Gas: The Power and Fragility of Networked Protest, New Haven: Yale University Press.

Unger, B. (1993). Sacred Hunger, London: Hamish Hamilton.

Wu, T. (2016). The Attention Merchants: The Epic Scramble to Get Inside Our Heads, New York: Alfred A. Knopf.

Shoshana Z. (2019a). The Age of Surveillance Capitalism: The Fight for a Human Future at the New Frontier of Power, New York: Public Affairs.

- (2019b) "It is not that we've failed to rein in Facebook and Google. We've not even tried," The Guardian, July 2, 2019. Accessed July 2.

https:/www.theguardian.com/commentisfree/2019/jul/02/facebook-google-data-changeour-behaviour-democracy 
- (1988). In the Age of the Smart Machine: The Future of Work and Power, New York: Basic Books. 